\title{
Perancangan Dan Pembuatan Mobile Robot Smart Trash Bin Berbasis Bluetooth HC-05
}

\author{
${ }^{1}$ Mohamad Syafaat, ${ }^{2}$ Wulan Fitriani Safari, ${ }^{3}$ Syafrima Wahyu \\ ${ }^{1,2,3}$ Universitas Binawan/Fakultas Sains dan Teknologi, J1.Raya Kalibata, Jakarta Timur, 021-80880882 \\ Email: syafaat@binawan.ac.id, wulan.fitriani@binawan.ac.id, syafrima@binawan.ac.id \\ Email Korespondensi: syafrima@binawan.ac.id
}

\begin{abstract}
Garbage is a problem that must be handled properly. Currently, technology and information are also used to assist waste management, namely the Smart Trash Bin. In this research, the design and construction of the Mobile Smart Trash Bin is carried out. The design of this smart trash bin not only has an automatic function to open and close the trash can, but also has a mobile function that allows the trash can to move closer to the person who is going to throw garbage. A smart trash bin mobile robot system is designed using a photodiode sensor as a line reader (track robot) and a servo motor is used to open and close the trash can. In addition, Bluetooth HCO5 is used to activate the robot via voice commands from an android smartphone. The mobile robot smart trash bin runs according to the system designed.
\end{abstract}

Keywords: Bluetooth, Mobile Smart Trash Bin

\section{Abstrak}

Sampah merupakan permasalahan yang harus mendapatkan penangan yang tepat. Saat ini, teknologi dan informasi juga digunakan untuk membantu pengelolaan sampah yaitu dengan adanya tempat sampah pintar (Smart Trash Bin). Pada penelitian ini dilakukan perancangan dan pembuatan Mobile Smart Trash Bin. Rancangan smart trash bin ini tidak hanya memiliki fungsi otomastiasi buka tutup tempat sampah tetapi juga dilengkapi fungsi mobile yng memungkinkan tempat sampah untuk bergerak mendekati orang yang akan membuang sampah. Dirancang suatu sistem mobile robot smart trash bin dengan menggunakan sensor fotodioda sebagai pembaca garis (track robot), motor dc sebagai penggerak mundur maju robot dan motor servo digunakan untuk membuka dan menutup tempat sampah. Selain itu, Bluetooth HC05 digunakan untuk mengaktifkan robot melalui perintah suara dari smartphone android. Mobile robot smart trash bin berjalan sesuai dengan sistem yang dirancang.

Keywords: Bluetooth, Mobile Smart Trash Bin

\section{PENDAHULUAN}

Sampah menjadi masalah yang semakin lama semakin serius. Jumlah sampah semakin meningkat seiring dengan pertambahan jumlah penduduk dan peningkatan kegiatan ekonomi. Permasahan sampah harus mendapatkan penangan yang tepat. Penangan ini perlu dilakukan agar tidak menimbulkan permasalahn lebih luas baik bagi kesehatan, keindahan dan juga kenyamanan. Masalah sampah berkaitan erat dengan dengan pola hidup serta budaya masyarakat itu sendiri. Sampah menjadi masalah yang besar karena masih kurangnya kesadaran masyarakat untuk menjaga kebersihan dan membuang sampah pada tempatnya. Oleh karena itu penanggulangan sampah bukan hanya urusan pemerintah semata akan tetapi penanganannya membutuhkan partisipasi masyarakat secara luas (Sahil et al., 2016). Masyarakat sebagai penghasil sampah merupakan aktor utama dalam pengelolaan sampah. Untuk itu masyarakat perlu diberdayakan agar mampu melakukan berbagai upaya penanganan sampah yang bermanfaat bagi diri sendiri maupun lingkungan (Aryenti et al., 2014).

Penyediaan tempat sampah menjadi salah satu upaya dalam Pengelolaan persampahan. Hasil penelitian menunjukkan bahwa ada hubungan signifikan antara keberadaan tempat sampah dengan tindakan ibu rumah tangga dalam pemilahan sampah 
(Padmita \& Marwati, 2019). Saat ini, teknologi dan informasi juga digunakan untuk membantu pengelolaan sampah yaitu dengan adanya tempat sampah pintar atau biasa disebut dengan Smart Trash Bin. Tempat sampah yang dulu hanya berfungsi sebagai penampung sampah, kini telah dipadukan dengan teknologi dengan menambahkan fungsi tertentu. Penambahan fungsi otomatisasi buka tutup tempat sampah sudah banyak dilakukan seperti pada rancang bangun tempat sampah pintar (smart trash bin) berbasis Arduino Uno yang menggunakan sensor HC-SR04 di Univeritas Maarif Hasyim Latif (Sukarjadi et al., 2017), tempat sampah pintar dengan sensor HCRSF04 berbasis Arduino Uno R3 di SDN Tridayasakti 02 Tambun Selatan (Wuryanto et al., 2019), tempat sampah pintar di Universtas Labuhanbatu yang menggunakan sensor ultrasonic (Purnama et al., 2020).

Selain fungsi otomatisasi, tempat sampah pintar juga ada yang dilengkapi dengan fungsi pengiriman informasi. Informasi yang dikirim kepada petugas kebersihan adalah informasi keadaan tempat sampah sehingga pengelolaan sampah menjadi lebih efisien. Fungsi pengiriman informasi digunakan pada perancangan dan pembuatan Sistem Smart Trash Can berbasis android (Faisal, 2017), tempat sampah pintar yang mengirimkan pemberitahuan berupa e-mail kepada petugas kebersihan yang akan mengumpulkan sampah (Bowo et al., 2019), sistem monitoring sampah rumah tangga berbasis Wireless Sensor Network (WSN) (Syaifudin et al., 2019) dan tempat sampah pintar yang mengirimkan pemberitahuan berupa SMS (Fatmawati et al., 2020).

Perancangan dan pembuatan yang sudah dilakukan hanya menambahkan fungsi otomatisasi buka tutup tempat dan sampah dan penyampaian informasi dan belum ada yang mengunakan fungsi mobile. Oleh karena itu, peneliti ingin merancang dan membuat Mobile Robot Smart Trash Bin berbasis Bluetooth HC-05. Rancangan Smart Trash Bin ini tidak hanya memiliki fungsi otomastiasi buka tutup tempat sampah tetapi juga dilengkapi fungsi mobile yang memungkinkan tempat sampah untuk bergerak mendekati orang yang akan membuang sampah.

\section{METODE PENELITIAN}

Penelitian ini dilakukan dalam beberapa tahapan, yaitu perancangan sistem, pembuatan alat dan pengujian subsistem dan sistem secara keseluruhan.

\section{Perancangan Sistem}

Secara garis besar Blok diagram Mobile Robot Smart Trash Bin berbasis Bluetooth HC-05 dapat dilihat pada gambar 1 . 


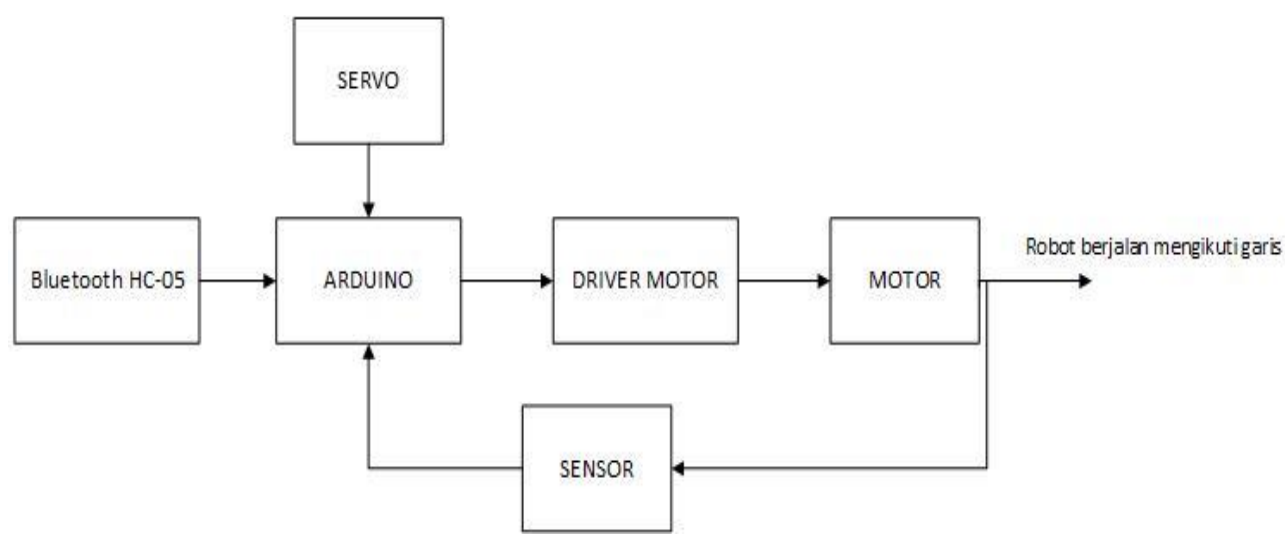

Gambar 1 Blok diagram Sistem Mobile Robot Smart Trash Bin

Sensor yang digunakan adalah sensor pengukur warna garis melalui Infrared sebagai Transmitter dan Photodiode sebagai Receiver. Kemudian output yang dihasilkan akan dibaca oleh Arduino melalu port ADC. Port ADC digunakan untuk mengkonversi keluaran sensor dari sinyal analog menjadi sinyal digital. Arduino berfungsi untuk mengatur gerakan motor melalui driver motor saat sensor garis mendeteksi garis dan mengaktifkan servo untuk membuka tutup tempat sampah. Adapun Bluetooth HC-05 digunakan untuk mengaktifkan robot dengan perintah suara melalui aplikasi Android.

Tahapan awal yang dilakukan sistem tersebut yaitu mengoneksikan Bluetooth HC05 ke android untuk mengaktifkan robot dengan perintah suara, kemudian mengetahui keluaran sensor dimana keluaran sinyal analog dari sensor akan dibaca oleh ADC arduino dan masukan tersebut dikonversi menjadi sinyal digital. Jika nilai ADC yang dibaca sama dengan parameter yang ditentukan maka motor DC akan bergerak sesuai instruksi yang diinginkan. Untuk mengendalikan pergerakan dari motor DC menggunakan driver motor, dimana segala pergerakan akan dijalankan sesuai dengan instruksi yang telah diprogram ke Arduino. Ketika Mobile Robot Smart Trash Bin telah sampai pada titik pemberhentian, sensor memerintahkan driver motor untuk berhenti kemudian motor servo aktif dan membuka tutup tempat sampah selama beberapa detik lalu tertutup kembali. Gambar 2 adalah flowchart secara keseluruhan dari sistem yang dirancang. 

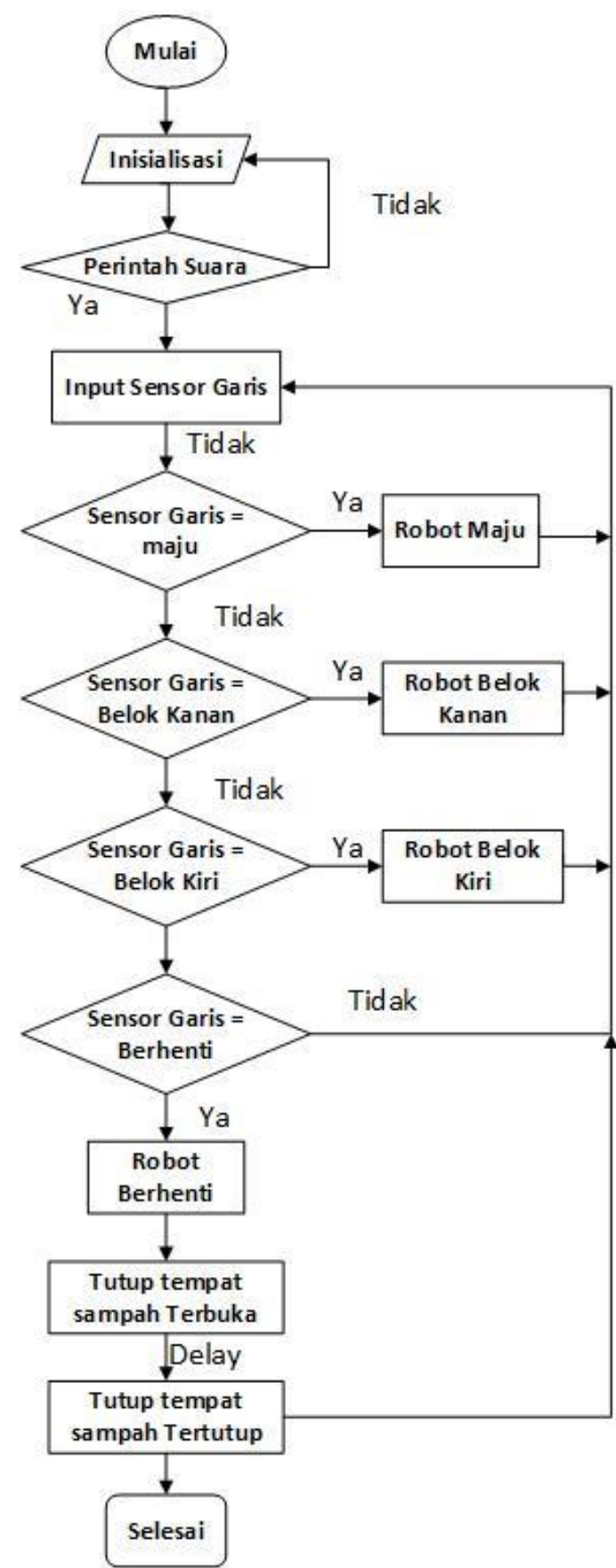

Gambar 2 Flowchart Sistem Robot Smart Trash bin

\section{HASIL DAN PEMBAHASAN}

Dalam menganalisa rancangan Mobile Robot Smart Trash Bin ini, dilakukan dengan menguji dari tiap-tiap unit bagian rangkaian untuk mendapatkan hasil apakah alat yang dirancang sesuai dengan yang diharapkan. Pengujian rangkaian yang dilakukan adalah sebagai berikut: 


\section{Pengujian Sensor Photodioda}

Pengujian sensor photodioda dilakukan dengan menampilkan nilai keluaran ADC dari setiap sensor. Untuk pengujian sensor dilakukan pada bidang warna putih dan bidang warna hitam. Tabel berikut adalah data nilai ADC yang diperoleh dari setiap sensor.

Tabel 1 Pengujian nilai ADC pada bidang Hitam

\begin{tabular}{cc} 
Sensor & $\begin{array}{c}\text { Nilai } \\
\text { ADC }\end{array}$ \\
\hline S1 & 1811 \\
\hline S2 & 1003 \\
\hline S3 & 994 \\
\hline S4 & 1015 \\
\hline
\end{tabular}

Tabel 2 Pengujian nilai ADC pada bidang Putih

\begin{tabular}{cc}
\hline Sensor & $\begin{array}{c}\text { Nilai } \\
\text { ADC }\end{array}$ \\
\hline $\mathrm{S} 1$ & 933 \\
\hline $\mathrm{S} 2$ & 910 \\
\hline $\mathrm{S} 3$ & 898 \\
\hline $\mathrm{S} 4$ & 885 \\
\hline
\end{tabular}

\section{Pengujian Driver Motor}

Pengujian ini dilakukan pada motor untuk pergerakan Mobile Robot Smart Trash Bin yang bertujuan untuk mengetahui kesesuaian kerja software dengan hardware yang telah dibuat. Pengujian pada motor sebagai pergerakan Mobile Robot Smart Trash Bin untuk control arah putaran motor yang dikendalikan dengan driver motor dilakukan dengan cara pengambilan data dalam keadaan high atau low pada port arah perputaran motor untuk pergerakan robot. Berikut data pengujian pada motor kanan dan motor kiri:

Tabel 3 Pengujian Putaran Motor Kanan

\begin{tabular}{ccl}
\hline \multicolumn{2}{c}{ Motor Kanan } & \multicolumn{1}{c}{ Keterangan } \\
Port D2 & Port D3 & \multicolumn{1}{c}{} \\
\hline 1 & 0 & Searah jarum Jam \\
\hline 0 & 1 & $\begin{array}{l}\text { Berlawanan Arah Jarum } \\
\text { jam }\end{array}$ \\
\hline
\end{tabular}

Tabel 4 Pengujian Putaran Motor Kiri

\begin{tabular}{ccl}
\hline \multicolumn{2}{c}{ Motor Kiri } & \multicolumn{1}{c}{ Keterangan } \\
Port D0 & Port D1 & \multicolumn{1}{c}{} \\
\hline 1 & 0 & Searah jarum Jam \\
\hline 0 & 1 & $\begin{array}{l}\text { Berlawanan Arah Jarum } \\
\text { jam }\end{array}$ \\
\hline
\end{tabular}


Dari hasil pengujian pada Tabel 3 diketahui bahwa jika port D2 diberi logika 1 dan port D3 diberi logika 0 maka respon putaran motor searah jarum jam. Sedangkan jika port D2 diberi logika 0 dan port D3 diberi logika 1 maka respon putaran motor berlawanan arah jarum jam. Begitu juga dengan hasil pengujian pada Tabel 4, jika port D0 diberi logika 1 dan port D1 diberi logika 0 maka respon putaran motor searah jarum jam. Sedangkan jika port D0 diberi logika 0 dan port D1 diberi logika 1 maka respon putaran motor berlawanan arah jarum jam. Selanjutnya dilakukan pengujian terhadap kedua motor. Hasil pengujiannya adalah sebagai berikut:

Tabel 5 Pengujian Respon Kedua Motor

\begin{tabular}{ccccc}
\hline \multicolumn{2}{c}{ Motor Kanan } & \multicolumn{2}{c}{ Motor Kiri } & \\
PORT & PORT & PORT & PORT & Respon Motor \\
D2 & D3 & D0 & D1 & \\
\hline 1 & 0 & 1 & 0 & Maju \\
\hline 0 & 1 & 0 & 1 & Mundur \\
\hline 1 & 0 & 0 & 1 & Belok kiri \\
\hline 0 & 1 & 1 & 0 & Belok Kanan \\
\hline 0 & 0 & 0 & 0 & Berhenti \\
\hline
\end{tabular}

Dari hasil pengujian pada Table 5, didapatkan input logika yang sesuai dengan yang diinginkan. pengujian selanjutnya yaitu dengan menguji PWM (Pulse with Modulation) motor dengan perbedaan variasi sudut. Tabel 6 adalah hasil pengujian PWM terhadap variasi sudut:

Tabel 6 Pengujian Respon Motor Terhadap Variasi Sudut

\begin{tabular}{cc}
\hline Sudut $\left(^{\mathbf{}}\right)$ & Keterangan \\
\hline 0 & Mampu \\
\hline 10 & Mampu \\
\hline 20 & Mampu \\
\hline 30 & Mampu \\
\hline 40 & Mampu \\
\hline 50 & Mampu \\
\hline 60 & Mampu \\
\hline 70 & Mampu \\
\hline 80 & Mampu \\
\hline 90 & Mampu \\
\hline 100 & Tidak Mampu \\
\hline
\end{tabular}

Dari Tabel 6 diketahui bahwa respon pergerakan motor terhadap variasi sudut jalur yang diberikan terhadap PWM yaitu $180 \mathrm{rpm}$ pada sudut $0^{\circ}-90^{\circ}$, robot masih mampu 
berjalan dengan PWM yang sama dan pada sudut $100^{\circ}$ sudah tidak mampu berjalan

\section{Pengujian Transmisi Bluetooth HC-05}

Pengujian transmisi Bluetooth HC-05 dilakukan untuk melihat seberapa kemampuan jarak dan waktu yang diperlukan modul Bluetooth HC-05 dapat mengirim perintah dari smartphone untuk mengaktifkan Mobile Robot Smart Trash Bin. Pengujian dilakukan dengan dua kondisi berbeda, yaitu pengujian akses handphone tanpa halangan dan akses menggunakan halangan dengan penghalang berupa tembok.

Tabel 7 Pengujian Transmisi Bluetooth HC-05

\begin{tabular}{cccccccc}
\hline & \multicolumn{3}{c}{ Kondisi Tanpa } & \multicolumn{4}{c}{ Kondisi Dengan } \\
Halangan \\
No & $\begin{array}{l}\text { Jarak } \\
\text { (Meter) }\end{array}$ & Status & $\begin{array}{c}\text { Pairing } \\
\text { Time } \\
\text { (Sekon) }\end{array}$ & $\begin{array}{c}\text { Kondisi } \\
\text { Saklar }\end{array}$ & Status & $\begin{array}{c}\text { Pairing } \\
\text { Time } \\
\text { (Sekon) }\end{array}$ & $\begin{array}{c}\text { Kondisi } \\
\text { Saklar }\end{array}$ \\
\hline 1 & 1 & Terhubung & 1,53 & ON & Terhubung & 2,98 & ON \\
\hline 2 & 2 & Terhubung & 3,21 & ON & Terhubung & 4,01 & ON \\
\hline 3 & 3 & Terhubung & 5,48 & ON & Terhubung & 6,09 & ON \\
\hline 4 & 4 & Terhubung & 6,62 & ON & Terhubung & 7,77 & ON \\
\hline 5 & 5 & Terhubung & 8,09 & ON & Terhubung & 10,38 & ON \\
\hline
\end{tabular}

\section{Pengujian Keseluruhan Sistem}

Pengujian seluruh sistem dilakukan dengan melihat tingkat keberhasilan sistem dari pengaturan parameter masukan nilai ADC pada setiap sensor, hingga keluaran sistem berupa respon gerakan motor DC terhadap jalannya Mobile Robot Smart Trash Bin. Pengambilan data dilakukan dengan merubah parameter ADC pada masing- masing sensor sehingga akan diketahui eksekusi dari sistem. Untuk parameter ADC yang digunakan untuk eksekusi program yaitu nilai $\mathrm{ADC}<950$ untuk mendeteksi bidang putih dan nilai ADC $>950$ untuk mendeteksi garis hitam. Hasil dari pengujian keseluruhan data sensor terhadap respon motor dapat dilihat pada Tabel 8 . 
Tabel 8 Pengujian Data Sensor Terhadap Jalan Robot

\begin{tabular}{ccccc}
\hline \multicolumn{5}{c}{ Sensor } \\
S1 & S2 & S3 & S4 & Jalan Robot \\
\hline$<950$ & $<950$ & $<950$ & $>950$ & Maju \\
\hline$<950$ & $<950$ & $<950$ & $<950$ & Maju \\
\hline$<950$ & $<950$ & $<950$ & $>950$ & Maju \\
\hline$<950$ & $<950$ & $<950$ & $<950$ & Maju \\
\hline$<950$ & $<950$ & $<950$ & $>950$ & Maju \\
\hline$<950$ & $<950$ & $>950$ & $>950$ & Maju \\
\hline$<950$ & $<950$ & $>950$ & $>950$ & Maju \\
\hline$<950$ & $<950$ & $<950$ & $<950$ & Maju \\
\hline$<950$ & $<950$ & $>950$ & $<950$ & Maju \\
\hline$>950$ & $>950$ & $>950$ & $>950$ & Maju \\
\hline$<950$ & $<950$ & $<950$ & $<950$ & Maju \\
\hline$<950$ & $<950$ & $<950$ & $<950$ & Belok Kiri \\
\hline
\end{tabular}

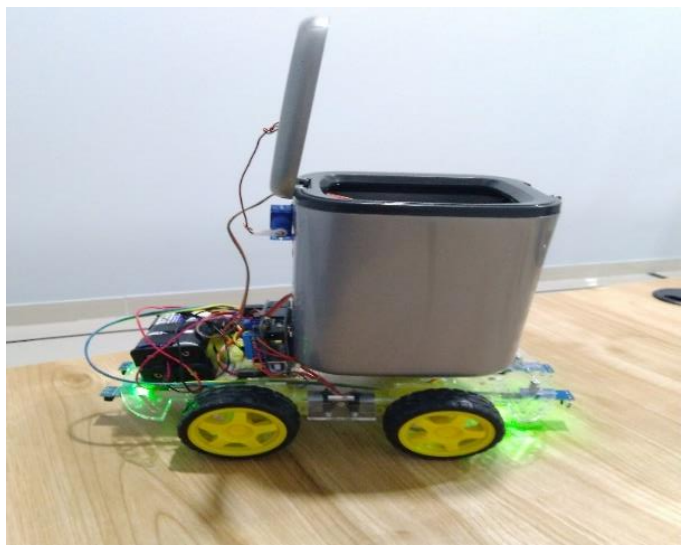

Gambar 3 Mobile Robot Smart Trash bin

\section{SIMPULAN DAN SARAN}

Mobile Robot Smart Trash Bin berjalan sesuai dengan sistem yang dirancang. Respon pergerakan robot terhadap variasi sudut jalur yang diberikan terhadap PWM yaitu $180 \mathrm{rpm}$ pada sudut $0^{\circ}-90^{\circ}$, robot masih mampu berjalan dengan PWM yang sama dan pada sudut $100^{\circ}-180^{\circ}$ sudah tidak mampu berjalan.

\section{DAFTAR PUSTAKA}

Aryenti, Kustiasih, T., Mulyanto, \& Lesmana, Rudy. Setyono, P. dan S. (2014). Sistem Informasi Untuk Layanan Persampahan Di Kota Surakarta. Permukiman, VI(2), 8997. 
Bowo, W. Y., Sutabri, T., \& Faturahma, L. (2019). Tempat sampah pintar dengan notifikasi berbasis iot. Jurnal Teknologi Informatika Dan Komputer I, 5(2), 50-57.

Faisal.(2017). Aplikasi Smart Trash Can Dalam Mengatasi Persoalan Sampah Secara Mobile

Berbasis Android. Jurnal Instek, 2(2), 1--10.

Fatmawati, K., Sabna, E., \& Irawan, Y. (2020). Rancang Bangun Tempat Sampah Pintar Menggunakan Sensor Jarak Berbasis Mikrokontroler Arduino. Riau Journal Of Computer Science, 6(2), 124-134.

Padmita, N. L. P., \& Marwati, N. M. (2019). Hubungan tingkat pengetahuan dan keberadaan tempat sampah dengan tindakan ibu rumah tangga dalam pemilahan sampah. Kesehatan Lingkungan, 9(2), 161-170.

Purnama, I., Harahap, S., \& Ritonga, A. (2020). Rancang Bangun Tempat Sampah Otomatis Pada Universitas Labuhanhati. Informatika : Fakultas Sains dan Teknologi, $8(2), 81--84$.

Sahil, J., Muhdar, M., Rohman, F., \& Syamsuri, I. (2016). Waste management at Dufa Dufa subdistrict, City of Ternate (in Bahasa Indonesia). BIOeduKASI, 4(2), 478-487.

Sukarjadi, Setiawan, D. T., Arifiyanto, \& Hatta, M. (2017). Perancangan Dan Pembuatan Smart Trash Bin Berbasis Arduino Uno Di Universitas Maarif Hasyim Latif. Teknika: Engineering and Sains Journal, 1(2), 101-110.

Syaifudin, M., Rofii, F., \& Qustoniah, A. (2019). Rancang Bangun Sistem Monitoring Tempat Sampah Rumah Tangga Dan Penerangan Jalan Berbasis Wireles Sensor Network (Wsn). Transmisi, 20(4), 158. https://doi.org/10.14710/transmisi.20.4.158166

Wuryanto, A., Hidayatun, N., Rosmiati, M., \& Maysaroh, Y. (2019). Perancangan Sistem Tempat Sampah Pintar Dengan Sensor HCRSF04 Berbasis Arduino UNO R3. Paradigma, 21(1), 55--60. 